Title: Constructing Physical Fights: An Interactionist Analysis of Violence among Affluent, Suburban Youth

\author{
Author: \\ Curtis Jackson-Jacobs, $\mathrm{PhD}$ \\ Department of Crime, Law, and Justice \\ University of Illinois at Chicago
}

Author Bio: Curtis Jackson-Jacobs received his PhD in Sociology from UCLA in 2009. His research has focused on college student 'crack' cocaine users, American street gangs, violence among affluent youth, and video recordings of violent encounters.

\begin{abstract}
Based on more than four years of ethnographic fieldwork and a dataset of 189 violent encounters, this article explores the social phenomenology of physical fights in a novel setting. Although American sociologists have traditionally depicted violence as a distinctively 'ghetto' phenomenon, the members of this sample were overwhelmingly white and affluent. Since the usual explanatory background factors - race, poverty, and neighborhood - cannot adequately account for their violent experiences, the dataset is especially valuable for analyzing the generic interactional processes through which physical fights unfold. Furthermore, the article suggests a model that runs counter to the prevailing sociological perspective that violence is universally motivated by independent, preexisting conflicts. Oftentimes, the sample members set out to "get into" fights for their perceived experiential rewards and only later instigated disputes as a means to motivate and justify violent action. Using the method of analytic induction, the article presents
\end{abstract}


a generalizable theory of how fights unfold in interaction. Three stages were necessary for achieving a fight: (1) agreeing to fight as a solution to a challenge to "interpersonal sovereignty," (2) transcending the ordinary fear of violence, and (3) using competitive techniques of violence.

Acknowledgments: This project received funding from The Harry Frank Guggenheim Foundation and the UCLA Graduate Division.

The author appreciates comments from Randall Collins, Robert Emerson, Robert Garot, Jack Katz, Mark AR Kleiman, Calvin Morrill, and several anonymous reviewers at Qualitative Sociology.

Previous versions of this paper were presented at the American Sociological Association Convention (2003), the University of Pennsylvania (2005), Northern Illinois University (2006), and UCLA $(2006,2009)$.

The present version appeared in the May 2013 issue of Qualitative Sociology. 
Watching from a safe distance, physical fights can appear inhuman and animalistic, group fights especially. It can be hard to tell who is fighting whom, much less why. Arms swing and heads bounce. Projectiles fly. People run around frantically. And the noises-sounds one never knew humans could make. Everyday language aptly conveys this sense of chaos and disorder. Fights are called "free-for-alls," “dust-ups," and "knock-down, drag-out brawls." They "erupt” and "break out," like forces of nature, as if beyond the limits of social order - a view sustained by many psychological and biological theories of violence, and only rarely challenged by sociologists.

What to make of these beasts with four-fists?

Looking more closely, fights are prime sites for studying what is most human about humans: social interaction that is thoroughly meaningful and organized at each moment (Blumer 1969; Garfinkel 1967; Goffman 1967; Katz 1999; Mead 1934/1962; Schutz 1962). To contribute to the sociology of interpersonal conflict and violence, I document a theoretically strategic phenomenon: physical fights in a sample of overwhelmingly white, suburban, affluent youth.

My sample members defined a "fight" much as the broader culture does: a stretch of serious competitive violence (Jackson-Jacobs 2009). ${ }^{1}$ This definition served as both an interpretive lens for defining situations and also a practical guide for organizing action (Garfinkel 1967; Polanyi 1958; Sacks 1967-1968/1992; Schutz 1962). In the cases I describe, members specifically meant to do their violence as fights - rather than, say, unilateral beatings-

\footnotetext{
${ }^{1}$ I refer to the young people about whom I write as members in two senses of the term: as members of my research sample, but also as members of a particular culture, with its own boundaries, practices, and shared knowledge. As much as possible, I tried to organize my sample to follow natural categories of membership in friendship networks.
} 
thus constructing themselves as competitive opponents rather than sadistic predators.

American sociology, like popular culture, tends to depict youth violence as a distinctively "ghetto" phenomenon. Since the background factors usually presumed to cause violence are absent in my sample, the data are strategically valuable for highlighting the general process of constructing physical fights in face-to-face interaction. Thus, following the tradition of “interactionist” studies of violence (especially Katz 1988; see also Collins 2008), I seek an explanation that lies closer to and within the moments of violence.

Although I make general claims about fighting, I report evidence from a single ethnographic study for two reasons. First, I report on this sample to debunk the perspective that violent youth cultures are exclusive to contexts of poverty. Second, I present the evidence as an empirical contribution to the comparative backdrop of studies that have described qualitatively similar fights across race, class, and gender lines, and in diverse neighborhood, institutional, historical, and geographical contexts (e.g., Anderson 1999; Athens 1997; Brown 2010; Collins 2010; Conley 1999; Farrington, Berkowitz, and West 1982; Garot 2010; Gorn 1985; Hagedorn 1988; Horowitz and Schwartz 1974; Jones 2010; King 2005; Monkkonnen 2001; Polk 1999; Sanders 1994; Short and Strodtbeck 1968; Tomsen 1997; Winlow and Hall 2006). In the spirit of analytic induction (Znaniecki 1934), grounded theory (Glaser and Strauss 1967), and the comparative method (Ragin 2008), my purpose is to highlight what is common across contexts without losing sight of what is unique.

Whether fights occur in settings such as those I describe or in impoverished, workingclass, or "gang" contexts, the actors often pursue them as an opportunity to experience thrilling “action" (Garot 2007; Katz 1988, chap. 4; see also Goffman 1967), to "test" or demonstrate one's emotional and violent skills (Brown 2010, 186; Garot 2007a; Sanchez-Jankowski 1991), 
and to achieve the narrative payoffs and prestige of storytelling (Collins 2010; Jackson-Jacobs 2004a; Katz 1988, chap. 4; Morrill et al. 2000).

To be sure, there are differences in the interactional repertoires for provoking fights, the ways violent emotions are generated, and the bodily techniques of violence across contests and categories of actors. Gang members may challenge other youth by demanding to know the other's affiliation (Garot 2007a, 2010). Young men and women living in impoverished urban neighborhoods may be particularly sensitive to how their violent performances will affect the "respect" they receive from their peers (Anderson 1999; Jones 2010). Women may be more likely than men to tear clothing, pull hair, and strike each other open-handed rather than with closed fists (Jackson-Jacobs 2011). Yet these variations fall within the more generic process of socially organizing fights that I describe below.

Since fights involve mutual combat by definition, I analyze the fight as a fundamentally collective phenomenon. I outline three individually necessary and collectively sufficient stages in the process of organizing a fight — an explication of the fighter's tacit knowledge about how fights work. The model below constitutes a causal "recipe" in two senses (Gasking 1955): in Schutz's (1962; Schutz and Luckman 1973) sense of the practical knowledge used to create a fight in interaction, and in Ragin's (2008) sense of the conditions used to construct a sociological explanation.

To construct and sustain a physical fight, opponents must do the following:

$$
\text { 1. Agree to solve a mutual challenge to "interpersonal sovereignty" with a fight. }
$$

Whatever the substantive matter, disputants must transform a conflict into a challenge to sovereignty over the self - that is, the right of autonomy over body and identity, and the responsibility to defend one's selfhood. To achieve this definition of conflict, disputants must 
come to feel provoked by ritual or "remedial" matters rather than simply substantive offenses (Goffman 1971). Implicitly or explicitly, disputants must agree to resolve the crisis of selfhood with a fight.

2. Transcend the ordinary fear of using violence. In ordinary interaction, virtually everyone feels considerable tension and fear in anticipation of using violence. Overcoming the “confrontational tension/fear" (Collins 2008) that surrounds violence is not simply an individual phenomenon. Instead, it depends on the disputants creatively exploiting situational resources, often in collaboration with audience members. To transcend fear, disputants must provoke one another to reinterpret the immediate present as an urgent "last chance" crisis—one requiring violence right now.

3. Use competitive techniques of violence. Not any violence will do. To sustain a fight, it must be performed competitively. Standard competitive bodily practices include making one's own body vulnerable, fighting back-and-forth, and stopping upon victory.

Not only do my sample members' socioeconomic backgrounds rule out various explanations of their violence, but the interactional process itself also demands a refinement of theory. Prevailing theories portray violence as universally motivated by conflicts that exist prior to and independent of the violence (e.g., Black 1983, 1998), a notion premised on the view of conflict as motivated by objectively contradictory interests (see, e.g., Schelling 1960). It would be too simplistic, and often inaccurate, to describe conflict as the precipitating cause of fights in my dataset. In many cases, members went out "looking for a fight" before any conflict had begun or any opponent been selected. In every case, however, establishing conflict was a necessary ingredient in constructing the motivation to fight.

Furthermore, generating the necessary emotions was not simply a psychological 
phenomenon, but an interactional achievement (Katz 1999). Fighters do not simply get angry and "lose control," but instead collectively provoke violent emotions in one another (compare to Berkowitz 1989; Dollard et al. 1939; Freud 1907/1959; Gottfredson and Hirschi 1990; Wilson and Herrnstein 1985). Finally, the bodily practices of competitive fighting challenge the notions that conflict and cooperation are incompatible and that the intent of violence is exclusively to dominate or harm (see also Conley 1999; Labov 1972; Lee 2009; Luckenbill 1981; Pagliai 2000; Simmel 1905/1955).

\section{Sociology of Violence}

Physical fights outside of poverty contexts are novel to the sociological literature but, I argue, are not empirically unusual. How has such violence gone largely unnoticed by American sociology? Three inter-related methodological practices have shaped the theory and imagery of violence, highlighting extreme violent acts and impoverished actors while rendering the processes of commonplace, non-poor, non-minority violence invisible.

\section{Focusing on "Serious" Violence}

Sociological research emphasizes the most extreme forms of violent crime (e.g., homicide, which is strongly correlated with poverty and minority status), neglecting the more commonplace forms of interpersonal violence that transcend race, class, gender, and neighborhood. When fights and competitive violence have been studied at all, it has usually been in ways that either severely limit the range of variation or fail to highlight their distinctive processes. 
A number of interactionally-focused studies suggest that homicides often begin as fights, or at least with related phenomena such as "victim precipitation," "character contests," and “working agreements" to do battle (Katz 1988, chap. 1; Luckenbill 1977; Polk 1999; Wolfgang 1957). Yet very few fights end in homicide. Starting the analysis with cases ending in death and including cases that do not start as fights obscures the more general social processes of forging an agreement to do battle, sustaining that agreement, and ending violence without breaking it (Luckenbill 1977). Fights are distinctively competitive, a quality absent from enraged punitive attacks and slayings (Katz 1988). Indeed, as I argue below, the moment when a fight ends and an impassioned assault begins is the moment when competition is abandoned.

The quantitative literature is similarly oriented toward extreme, criminal violence. Hagan and Foster $(2001,879)$ illustrate the typical approach, specifically excluding fights from an analysis of youth violence because, they argue, "violence, other than simple fighting, is relatively infrequent." However, one might also argue the opposite. If the goal is to understand the spectrum of violence in social life, then the most common forms deserve attention, even if they are uncorrelated with the most extreme.

Another body of survey research, analyzed mainly within the discipline of public health, indicates that fighting is widespread across racial, class, and gender lines. On surveys, typically between one quarter and one half of American youth report fighting or similar violence in the past year (Centers for Disease Control and Prevention [CDC] 2012; Cheng et al. 2003; Espelage, Holt, and Henkel 2003; Paschall, Ennett, and Flewelling 1996; Saner and Ellickson 1996). The proportions do vary by race, class, and gender, but less than commonly presumed. Over the past 15 years, only about $1.1-1.4$ times as many nonwhite and lower-income youth reported fighting as did white and higher-income youth. In the CDC's (2012) most recent survey of high school 
students, $38 \%$ of white, $44 \%$ of Hispanic, and $46 \%$ of black males reported a past-year fight. Gender differences are indeed greater, but female fights are not rare events, with $20 \%$ of white, $29 \%$ of Hispanic, and $32 \%$ of black females reporting a fight. Researchers have nonetheless sustained the view of violence as an impoverished minority male phenomenon by emphasizing small (relative to public perceptions) but statistically significant differences, disregarding their substantial similarity.

2. Sampling the Poor and Marginal

Though there is evidence of widespread violence in all strata of youth cultures, both quantitative and qualitative sociologists have disproportionately designed their samples to over-represent convicts, the poor, and other marginalized groups. Ethnographic studies of American youth violence have predominantly focused on "gang" styles of violence and/or interpreted violence as a result of poverty (e.g., Anderson 1999; Hagedorn 1988; Horowitz and Schwartz 1974; Jones 2010; Sanchez-Jankowski 1991; Sullivan 1989; see also Katz and Jackson-Jacobs 2004).

In fact, inner city ethnographers have, at times, documented fights that are qualitatively similar to those outside of the ghetto. Anderson (1999, 69-90), for instance, distinguished between play fights, fair fights, ritualized group beatings, and serious assaults. Jones (2010) describes a similar range of fighting among inner city girls. Both describe fighting as a manifestation of what Anderson (1999) calls the "code of the street": The need to present oneself as willing and able to act violently as a means of personal protection and gaining respect (but see Garot 2007b).

The meanings and consequences of such inner city fights may differ from those in other 
social ecologies. Anderson (1999), for instance, argues that violent contests in "the streets" are zero-sum games: The victor gains respect, while the vanquished loses it (see also Short and Strodtbeck 1968). ${ }^{2}$ By contrast, even when my sample members had clearly lost a fight they oftentimes found some basis for framing the technical defeat as a moral victory (Jackson-Jacobs 2004a). Many of the more predatory forms of violence described in research on inner city youth violence, such as homicide, stickup, and kidnapping (Anderson 1999; Contreras 2013; Garot 2007a, 2010; Sullivan 1989), were absent or rare in my sample members' lives. Nonetheless, the categories of fights described in Anderson's research may be more generalizable than he acknowledges. Examples of each are present in my own dataset.

The most prominent exceptions to sampling the poor are descriptive studies of violence in skinhead, football/soccer "hooligan," and pub subcultures in Europe, Canada, and Australia (e.g., Baron 1997; Buford 1998; King 1995; Marsh, Rosser, and Harré 1978; Tomsen 1997; Winlow and Hall 2006). As in American studies of gang violence, most of this research describes fighting as totemic of the local culture (Katz and Jackson-Jacobs 2004). That is, the researchers report specific cases of fights and explore their local meaning, but rarely attempt to explain the generic process of organizing a fight in face-to-face interaction (but see Farrington, Berkowitz, and West 1982; King 1995). By varying the socioeconomic context, though, such studies do contribute to a general theory of fight processes, a point to which I return below.

\section{Privileging Background over Process}

Violence research has historically privileged the background of actors over the social processes

\footnotetext{
${ }^{2}$ But see Anderson $(1999,85-87)$ for an example in which both are described as gaining respect.
} 
of the violence itself. ${ }^{3}$ In much of sociology, the causes are presumed to be distant from the actual moments of violent action, whether in biographical hardship, subcultural group membership, or at least in independent, pre-existing "reasons" for conflict (Schinkel 2010). Even less common is focused attention to how the body itself is used to construct the meaning of violence, one element of my analysis (but see Collins 2008; Katz 1988, 1999).

Lost in these accounts are the fateful interactional contingencies of "doing" conflict (Emerson and Messinger 1977; Sacks 1992). One of the interactionist tradition's major contributions has been to document a spectrum of violent encounters constituted through distinctive situational and interactional processes (e.g., Garot 2007a; Jackson-Jacobs 2004a; Katz 1988; Luckenbill 1977, 1981; Newman 2004; Sanders 1994; see also Johnson 1995). To make distinctions between different types - such as impassioned slayings, drive-by shootings, and rampage killings — the sociological method requires evidence that the actors socially organize them to be different.

Evidence from the European studies illuminates an important quality of the fight process. Not only are the background factors traditionally associated with violence in American research absent, but so are the conventionally recognized reasons for conflict. Members of Farrington, Berkowitz, and West's (1982) sample of British delinquents, for instance, often reported being motivated by excitement and a desire to fight alongside friends, rather than by anger or a desire to dominate (contrast with Athens 2005). "Firms" of soccer fans plan to fight long before encountering their opponents (usually strangers), define the reasons for violence in patently

\footnotetext{
${ }^{3}$ Historical research provides some valuable exceptions (Gorn 1985; Monkkonen 2001). Conley (1999), for instance, describes "the agreeable recreation of fighting" in nineteenth century Ireland.
} 
arbitrary terms (supporting the opposing team), and elaborately provoke their rivals into attacking themselves (Buford 1998; Collins 2008; King 1995; Marsh, Rosser, and Harré 1978). As Katz (1988; Katz and Jackson-Jacobs 2004) argued of youth street gangs, by creating mutually opposed but otherwise similar teams, the firms invite the conclusion that the purpose of fighting is not to resolve or manage conflict, but instead that the purpose of conflict is to justify fights (compare to Black 1983, 1998).

Fights have a distinctively competitive, negotiated character that is difficult to reconcile with theoretical perspectives that presume violence is "pure" conflict (Simmel 1905/1955). Athens (2005), for instance, has critiqued Goffman (1967), Luckenbill (1977; see also 1981), and others for describing violence as sometimes involving cooperation and "character contests," rather than as universally oriented toward dominance. Black $(1983,1998)$ has classified virtually all violence as "self-help;" that is, social control or conflict management that punishes deviance (see also Cooney 1998).

My sample members, however, routinely planned to get into fights long before actually choosing someone with whom to fight, much less a reason to fight. Then, oftentimes, the ostensible reasons would be deliberately contrived (e.g., "accidental” bumps; see Katz 1988, chap. 3). Rather than saying violence was enacted to resolve independently existing conflicts, in many cases, it would be more accurate to say conflicts were manufactured to resolve the challenge of finding a fight. Members were cognizant of this process. Rick, one of the most active fighters in my sample during his teens and twenties, used to call the conflict an "excuse for abuse." In Schinkel's (2010) terms, this violence was at least partly "autotelic" (i.e., done for its own sake) or, more colloquially, "recreational" (Conley 1999; Zimring and Zeuhl 1986).

The most extensive theoretical discussion of fights may be Collins' (2008) broad study of 
violent situations. Collins documented several phenomena that overlap with the fights I describe, including "carousing violence," or fights "as fun" and "entertainment," and "fair fights." I draw on his central claim that any process of organizing violence consists largely of circumventing “confrontational tension/fear." There is, however, an important difference between my analytic strategy and Collins'. Collins focused on situational conditions that disproportionately lead to violence, thus setting aside the phenomenological differences between fights and other violence. My analysis more closely follows the methodological approach of Katz's (1988) phenomenological studies of violence, focusing on the interpretive, emotional, and practical dimensions of interaction.

\section{Sample, Setting, and Dataset}

I began this research with the premise that I had access to a strategic sample that would be novel to the existing literature (Merton 1987). As a high school student growing up in Tucson, Arizona, I knew many young men and women who regularly got into physical fights, most from an affluent, suburban neighborhood. During most of the fieldwork period (December, 1999 - June, 2004) I lived in Los Angeles (500 miles away), so I took frequent trips to Tucson over weekends and breaks in the academic calendar. To start, I asked several young adults (aged about 18 to 22) with whom I was still in contact to participate in a sociological study of fighting. I hung out with them at their homes and at bars and parties, where I then met their friends, sibling, and romantic partners, networking the sample out to include members of overlapping friendship circles.

I recorded fieldnotes on and/or interviews with 86 individuals, though I focused particularly on a core sample of 29 men and six women who formed a more or less stable and 
coherent primary group of friends during their teens and twenties (aged 18 to 28 during my research). My interviews covered the members' lives prior to fieldwork, extending the period of research back in time to childhood and adolescent experiences. In the core sample, $89 \%$ (31 out of $35 ; 26$ out of 29 men, 5 out of 6 women) claimed to have been involved in at least one fight between the time they started high school and the time that I ended my fieldwork.

Eighty percent (28 out of 35 ) of core sample members defined themselves as "whitealone;" 11\% (4) as white/Latino; and 3\% Asian alone (1), Asian/white (1), and Latino/Native American (1). ${ }^{4}$ Of those for whom I recorded parental occupation, half had at least one parent either in a professional career (10 out of 26; e.g., attorneys and physicians) or who owned a business (three out of 26). All but one grew up in a neighborhood with some of the Tucson area's highest property values and a prestigious—some would say pretentious - reputation.

As teenagers they viewed themselves as a rebellious troublemaking group of friends, and were apparently viewed as such by school officials. At least 11 dropped out of high school or were expelled, and 2 others graduated from an alternative school, whose students had quit or been kicked out of regular high school. Even so, at least 16 attended four-year universities during my fieldwork, including three of the high school dropouts and both alternative school graduates. At least five attained advanced degrees in law, business, social work, and social science.

During late youth (roughly, ages 16-25) they proudly saw their extended network as an eclectic group of "hip" and tough, but sometimes "square," social types, including college students, punk rockers, some who dabbled in gang membership, and, toward the periphery, a few members of skinhead groups (the nonracist kind; some were Latino and at least one was black;

\footnotetext{
${ }^{4}$ The population of Pima County, in which Tucson is located, was $61 \%$ non-Hispanic "whitealone," 29\% Latino (of any race), and 3\% black in the 2000 Census.
} 
two were white women, both of whom contributed firsthand accounts of violence to my dataset). ${ }^{5}$ All of the core members led active social lives organized around regular routines of drinking and partying, at least into their twenties. Most used illegal drugs at some point and all had at least a few friends involved in some degree of criminality (e.g., drug dealing, robbery, passing fake currency, illegal gambling).

They appreciated the incongruity between their "deviant" activities and conventional backgrounds, viewing fighting as an important mark of distinction. Dramatizing and transcending traditional status differences was central to their cultural habitus, a matter of pride and prestige (Boudieu 1984; see also Collins 2008, chap. 7; Grazian 2003; Katz 1988, 118-128; Jackson-Jacobs 2004b). It was important to members that the group be internally diverse. At the extreme, there was a time when one member was serving on an Ivy League law review while another served 18 months in an Arizona state prison. Even two people in such distant circumstances shared a common bond of organic solidarity (Durkheim 1912/1995): Both had at least one good friend at the opposite end of the institutional hierarchy of respectability.

Interaction-Level Dataset

\footnotetext{
${ }^{5}$ Those unfamiliar with skinhead cultures may not recognize that they are far more heterogeneous than commonly perceived (see Sarabia and Shriver 2004). There is evidence to suggest, in fact, that American skinheads began as a nonracist youth movement (Wood 1999). The skinheads I knew claimed to have had occasional encounters with racist or Neo-Nazi skinheads at concerts and other public events, typically resulting group fights or attacks against the racist skinheads.
} 
I accumulated an interaction-level dataset of 189 firsthand accounts of participation in violence and 51 near-violent situations, based largely on tape-recorded interviews, but also including 26 cases of violence that I observed firsthand. ${ }^{6}$ The greatest limitation of the interview data may be that accounts most directly reflect linguistic codes, storytelling practices, and cultural myths about fighting (Labov 1982; Morrill et al. 2000; Schegloff 1987). I triangulated accounts (Webb et al. 1966) by comparing recollections, observations, and, for 23 fights, between two and seven interviews from different actors. Most of my direct observations of violence (21 out of 26) took place prior to fieldwork. As a pilot project, I wrote retrospective observations (see Ferrell 1997, 2012; Lyng 1998; see also Athens 1997) on all violence I could recall witnessing or being involved in during the previous seven years. ${ }^{7}$

In an exploratory, inductive fashion (Glaser and Strauss 1967; Katz 1988, 2001), I coded all violent situations as including a fight (122 cases), other violence (94), and/or both (27); hence, the numbers add to more than 189 . Since the meaning of a situation is always contingent on what is happening right now, I did not assume that the same label should apply from "start" to “end.” Thus, I identified fights-turned-“jumpings” (i.e., group beatings) as one important phenomenon to explain.

I used the logic of sampling the most qualitatively diverse range of cases possible, rather than collecting a random sample or complete census of violent experiences (see Glaser and

\footnotetext{
${ }^{6}$ Unless noted as a fieldnote, direct quotes are from transcripts of audio recordings.

${ }^{7}$ I recorded fieldnote observations on 2 full-blown fights, 3 cases of other violence, and 13 near fights. I wrote retrospective observations on 18 fights that happened prior to the fieldwork, 3 cases of other violence, and 4 near fights. I wrote all retrospective observations in October 1999, and preserved them as originally written.
} 
Strauss 1967). Therefore quantitative inferences based on these data would be less reliable than the qualitative inferences I emphasize. To document the process of constructing a fight, I used the method of analytic induction (Katz 2001; see also Becker 1953; Cressey 1953; Garot 2010; Katz 1988, 1999; Lindesmith 1947; Znaniecki 1934). In contrast to probabilistic methods and some comparative techniques (see, e.g., Epstein and King 2002; Ragin 2008), in analytic induction one alternately revises both outcome and hypothesis until the explanation fits all known cases. Thus explanations are in the form of necessary and sufficient conditions, and of an exploratory rather than confirmatory nature. Through this process I reached an explanation specific to fighting, rather than a general theory of violence (see Athens 2005)

\section{The Process of Organizing a Fight}

How does a dispute turn into a physical fight? Why does the fight begin now? How does it end? How do some fights lead to more "serious" violence?

The process of creating and sustaining a fight unfolded over three individually necessary and collectively sufficient steps: (1) Establishing a provocative challenge to interpersonal sovereignty, and agreeing to fight as a solution; (2) Transcending the ordinary fear of using violence; and (3) Using competitive bodily techniques of violence. Members used their tacit knowledge of this process as a practical guide to action.

1. Agreeing to Solve a Challenge to Interpersonal Sovereignty with a Fight

Fights always involve conflict, but not just any conflict. What matters is not the substantive 
topic, but a particular turning point in the course of the dispute. However they began, conflicts leading to fights came to pose a provocative challenge to each disputant's right to control one's own self — one's body and identity — that is, the sovereignty of the self. Achieving this definition of a conflict requires a specific transformation of meaning, from viewing the situation as a substantive trouble to viewing it as ritual insult and fateful existential dilemma-a dare to "do something," to defend one's claim to selfhood (see also Emerson and Messinger 1977; Goffman 1971). The challenge poses a discrediting, humiliating threat should one "back down." At the same time, it also poses an aggrandizing opportunity to "stand up" for oneself and claim extraordinary personal competence.

To resolve the crisis of selfhood, directly or indirectly, one party proposes to fight and another makes a move to accept the proposal. Typically, agreements to fight are negotiated verbally over several turns of challenge and counterchallenge — what my sample members referred to as "talking shit." Disputants might also provoke one another with aggressive gestures and invasions of personal space or, in the case of eye contact, unwelcome intrusions threatening the right of freedom from scrutiny. Members of fighting cultures consider talking shit a prelude and implicit agreement to mutual violence.

\section{Challenging Selfhood}

Homicide researchers routinely comment that serious violence frequently follows utterly trivial disputes (e.g., Katz 1988, chap. 1; Luckenbill 1977; Monkkonen 2001; Polk 1999; Strauch et al. 2001; Wolfgang 1957; see also Conley 1999; Gorn 1985). To understand interpersonal violence one must confront both its gravity and its absurdity. People kill each other, for instance, after 
arguing about parking spaces or barbecued food (Katz 1988). But the content of the conflicts is misleading.

There is always something important at stake when people use violence (Girard 1977). In righteously impassioned punitive attacks, it is the defense of some version of "The Good" (Katz 1988). In competitive fights, it is the combatants' claim to interpersonal sovereignty: Disputants come to feel that their rights of selfhood have been attacked, that they have been dared to escalate the conflict and that the moral foundations of the self are on the line (see Anderson 1999; Goffman 1967; Garot 2007b, 2010). As I explain below, although aggressive instigators may have initiated a dispute disingenuously just moments before, they must nonetheless come to feel authentically motivated by it.

A critical turning point arises: Disputants come to feel provoked by procedural, remedial matters rather than simply by substantive offenses - that is, by how the other is disputing, rather than what they are disputing about (Goffman 1971; Labov 1982). The present situation is no longer a specific insult, but represents a violation of "general principle," a phrase familiar in some "street" circles (see also Katz 1988).

Case \#60, based on interviews with one combatant, four witnesses, and limited, corroborating queries of the other combatant, ${ }^{8}$ illustrates this point. When they were 22 years old, Jerry and Chad got into a fight after arguing over a carne asada burrito and guacamole. ${ }^{9}$ They were at Justin and Will's apartment late at night drinking with friends, celebrating a barroom brawl already gotten into with several strangers earlier in the evening (Case \#4). Jerry

\footnotetext{
${ }^{8}$ Tellingly, the "victor," Chad, was reluctant to provide an interview, apparently ashamed or regretful of having beaten a close friend.

${ }^{9}$ I use pseudonyms and conceal exact locations.
} 
and Chad drove to Nacho's Tacos, Tucson's beloved late-night Mexican fast food restaurant (and favored "staging ground" for fights [Anderson 1999]). Chad had a sensitive stomach and particular tastes, so he asked for the guacamole and other dressings to be served on the side. Jerry ordered the food, so Chad insisted that he make it a special order. Upon returning to the apartment, Chad sat down on the couch and opened his Styrofoam box of food. He inspected it for a moment. The guacamole was in the burrito. According to Jerry, Chad thought he "ordered his food wrong. And I thought I ordered it right and they messed up. So we started arguing about it."

Standing tensions in their relationship may have been relevant. According to Jerry, they already had a "history." Being "two of the biggest guys in the group," Jerry explained, "We're kind of competitive... Like, before, we've come sort of close to fighting. Just over stupid stuff." They hadn't actually fought "for real," but they had engaged in playful feats of strength, including what Jerry called "wrestling matches where everyone watched."

The previous day they had spent at least twelve hours in a car together on the drive to Tucson from San Francisco, where Jerry was studying philosophy at a private university and Chad was working full-time as a plumber. According to their friends, Chad felt Jerry had been acting academically superior. This wouldn't have been an entirely unusual complaint during Jerry's "metaphysical phase" (at the time, such complaints were occasionally voiced against many of those attending college, probably including myself).

A critical turning point came when Chad and Jerry started to view the argument as personally insulting, possibly in light of these previous tensions. Caroline recalled that Jerry was shouting something along the lines of "Don't tell me how it comes" and Chad was yelling things like "I'm not stupid" (emphasis added). By then, it seems, each saw the other as unfairly 
challenging his personal competence, and both were attempting to negate the challenge to selfhood in increasingly hostile fashion.

Jerry attempted a face-saving move. To simply walk away would have been too humiliating — an implicit admission that, not only could he not defend his own claims of personal competence and autonomy, but also that he had unfairly challenged Chad's. So, instead, as Jerry told me, he announced, "Well, I'm leaving. Cause otherwise I'm gonna have to kick your ass," and walked out of the apartment.

Jerry's move was a more complex solution to the dilemma than it might appear at first glance (even if a misguided one, given the outcome below). He was willing to exit the situation without a fight if he could have the last word, but his last word was an indirect proposal to fight, thus leaving Chad in an immediate crisis: Either accept the proposal to fight promptly, or suffer the enduring humiliation of taking the insult.

Chad took a quick moment to consider his next move, silently looking at his burrito while Jerry walked out. As fighters see it, failing to respond to an insult or challenge, in effect, admits to being unwilling or unable to defend one's right to dignity. What to do? Chad picked up the burrito, stormed outside, and shoved it right in Jerry's face. This was also a subtler move than one might think. It symbolically reversed their relative standing in the situation. Jerry had used the burrito to humiliate Chad and challenge his "face," in the figurative sense (Goffman 1967). Now, Chad was humiliating Jerry with the same burrito, stuffing it back into Jerry's face, literally. ${ }^{10}$ Jerry immediately grabbed Chad in a headlock. Chad broke free and punched him in the face several times. They were separated by friends after a few blows.

To understand the meaning of pre-fight conflicts, a particular observation is crucial:

\footnotetext{
${ }^{10}$ See also Foucault (1977, chap. 1) and Katz (1988, 34-36).
} 
Fights follow conflicts, but they do not attempt to resolve the explicit topics under dispute (contrast with Black 1983, 1998). By the time disputants start fighting, they have suspended the matters about which they were just arguing. They do not continue to debate specific offenses; afterwards, winners do not announce solutions to disagreements (such as, "See? You did order it wrong!"). The violence itself openly acknowledges that the preceding argument is closed and, in most cases, effectively ends any potential for resolving the substantive matter; above, the fight actually obliterated the disputed object.

Instead of resolving conflicts, fights try to solve an existential dilemma. Once sovereignty has been challenged, each side may feel that a "last stand in defense of the self" is required (Katz 1988, 19-22). It becomes difficult to "back down" without feeling that one is demonstrating cowardice, weak character, and a fundamental inability to defend the rights of selfhood (see Goffman 1967). Fighting is a particularly attractive solution because it transforms the situation from a potentially humiliating one into a potentially redeeming one - a dramatic opportunity to test one's character and demonstrate resolve and self-confidence, the same personal qualities under threat. In fact, as long as they perform honorably, fighting may be the only practical way for both sides to leave the contest seeing themselves as "winners," in a moral if not a technical sense. Such fights are not necessarily zero-sum games (compare to Anderson 1999; Short and Strodtbeck 1968).

\section{Provocation and Negotiation}

The "burrito fight" comes closer than the remaining cases to illustrating what most people imagine the typical fight to be. I refer to these as climactic-conflict fights, as they are the ultimate 
conclusions of disputes that began over substantive matters. By contrast, I describe most of the rest of the cases as brawls, or "fighting for fun" or "sport," as members would say. Beforehand, they would be out "looking for trouble." That is, the purpose of violence was specifically not to solve a conflict. The point was to generate conflict so one might reasonably, by the standards of this culture, get into a fight.

The mythology of many contemporary male cultures is that "sometimes you have to fight" (see Anderson 1999; Garot 2010). In a literal sense, however, fight situations virtually always allow various opportunities to avoid or exit the conflict (Garot 2007b, 2010). Yet, at least in young male culture, the normative obligation to accept challenges to fight can be exploited to provoke opponents who might privately wish not to. My sample members felt this obligation most powerfully in public school campus contexts. Even if one escaped the immediate conflictsituation, one would still be surrounded by one's antagonist(s) and peers who might sustain the provocation or treat the event as a moral failure (see Morrill et al. 2000).

Consider how Chad described the discrepancy between his external show of aggression and his private experience of fear in his "first big fight" in seventh grade. Word had gotten around through gossip that an eighth grader wanted to fight him. Chad was not sure why, but supposed it was because they liked the same girl:

\section{Case \#76. Chad's First Big Fight}

Chad: There's like hundreds of kids going around, "There's gonna be a fight," and I'm like scared. I don't want to fight this guy. I don't even know who the hell he is.... And I didn't know what to say. I was trying to save face, you know.... and I started talking a lot of shit.... So, they made sure we fought then. There's no way out of it. I couldn't back down, and he couldn't either. So we ended up meeting in the middle of the school. And he pretty much started pushing me over and over and over. And everyone's all, "Oooh!... Dude, are you gonna take that?" ... I was so scared-you know, scared shitless. And I'd never really hit anybody in the face before... I knew this guy was gonna swing at me and hit me. I ended up hitting him. (emphasis added) 
Though it backfired on him (Chad "won" the fight), Chad's instigator forced him to decide between fighting and relinquishing his claim to personal autonomy, possibly to be followed with a beating anyway. That instigators do this at all is an important point. As a strictly practical matter, it would be easier to simply attack a victim. But doing so would mean something very different. Beating someone unilaterally can easily come off as cheap and exploitative, while at the same time failing to show any competence beyond "being mean" (see also Katz 1988, chap. 3). To win a fight, however, is to cultivate a special kind of personal competence. Not only does it promise some degree of prestige, but it also elevates one to the status of "violent elite" (Collins 2008). It also provides the seductive opportunity to demonstrate to oneself the ability to conquer fear and stand up to daily life's onslaught of challenges, proclaiming and defending one's selfhood.

Regardless of the context, aggressive instigators frequently used insults and challenges to impose social and emotional costs on exit, such as loss of face and humiliation. Unwilling to pay these costs, many disputants agreed to violence only after being ensnared by intense provocation. Andy recounted using this strategy. He was in a high school computer class with Hank, a "jock" whom he considered annoying. Hank was messing with Andy's chair somehow, so Andy escalated the invasion of personal space, ramming the chair into Hank's knees. When Hank complained that he was hurt and would have to miss football practice, Andy taunted him. They initially agreed to fight but Hank later tried to back out. Andy provoked him further:

\section{Case \#33. Andy vs. the Football Player}

Andy: He was like, "That's it, we're gonna fight after school." And I was like, "That's fine by me." ... [Later] he came up to me and he was like, "It's okay, we don't have to fight. It was a misunderstanding." And I was like, "Whatever, bitch. I'm gonna be there. If you're not there then you're a pussy." And then he showed 
up and he kicked my ass.

Essentializing insults, that is, person-labels like asshole, attempt to denounce and denigrate the target's fundamental moral worth and dare the target to "do something" (see Garfinkel 1956; Katz 1974, 1988, 1999). To have one's identity publicly hijacked in such a fashion is a humiliating loss of control over the self (see Katz 1988, 24-26). Valerie provides an example from high school in which she made degrading comments about and insulted another student, who eventually confronted her publicly:

\section{Case \#77. Valerie Fights in the High School Cafeteria}

Valerie: I was calling [Brianna] a slut around school for about a week or two.... She would walk by me and I'd be like, "Slut! Whore!" ... And then finally, one day, it was in the middle of lunch, in the middle of the cafeteria.... "So, I hear you've been calling me a slut." And I'm like, "That's because I think you are a slut." And she's like, "Well, I think you're fat."

Valerie's account raises two important themes. First, both girls' insults are purposely public.

Second, they are gendered in quality. While Valerie uses the sexualized terms "slut" and "whore" to demean Brianna and provoke retaliation, Brianna casts Valerie's body-type as unattractive. Valerie continues:

She pushed me and I fell down on a chair ... I slammed a Coke in her face ... And she ripped my shirt open and, the only thing I remember hearing was Luca DeSalvo going, "Valerie's tits! Valerie's tits!" And the whole school saw my tits ... my shirt was wide open... I was trying to cover myself. And she was scratching my back... And I got up and punched her a couple times in the face.

Not only did the conflict begin with sexualized and gendered insults, but the violence itself also had a sexualized tone, with one combatant partially disrobing the other in front of an audience.

For young men, feminizing insults may have a special sting, especially when combined with a direct challenge to fight and the presence of an audience. Two examples from fights in 
carousing contexts:

Case \#5. TJ, Andrew, and I Brawl

Retrospective Observation: Andrew kept saying, "Fight me like a man." His opponent started punching him in the face. Andrew backpedaled ... saying, "If you fight like a girl, I'll slap you like a bitch."

\section{Case \#1. Brawl at the Midtown Club}

Charlie: He started calling us pussies. So my friend slapped him and said, "Now who's the bitch?"

Feminizing terms challenge the target's right to claim masculine character and to control his public self, symbolically transforming him into a lower social type and object of derision. Thus he can be disrespected and degraded with impunity and his suffering becomes a source of pleasure for others. To reclaim one's masculine character, it may feel as if only violence will do. Even if conflict was initially entered into voluntarily, violence may now feel compulsory.

For instigators, the value of humiliating provocations is not only that they incite retaliation, but that they also conceal their own coercive nature. As many active fighters see it, and many audience members assume, violence is consensual so long as the opponents agree to fight, even if it takes extensive and/or coercive provocation to achieve such "consent." Provocative as they are, pre-fight conflicts nonetheless involve negotiation. Disputants sometimes manage to establish "fair fights" through unspoken agreements. Oftentimes, however, they arrange to fight "fair" through explicit verbal agreements, extensively negotiating such things as the weapons and opponents allowed:

Case \#68. Aaron vs. The Cowboy

Aaron: I had these spikes on [a spiked ring]... he was like, "You better take those off." And I'm like, "No, fuck you!" And he goes and grabs a bottle and smashes it... And I'm like, "All right! All right! I'll take them off!" (emphasis added) 


\section{Case \#5. TJ, Andrew, and I Brawl}

Retrospective Observation: I pleaded with Andrew, "There's way too many of them." They heard me say this and [one of them] replied, "I don't give a fuck. We can do this shit one-on-one." (emphasis added)

Negotiating "fairness" in group fights is more challenging, in part because it is easier for additional combatants to "jump in" after the two principals have overcome the initial interactional and emotional obstacles to violence (see also Collins 2008). It may be difficult in practice to sustain an agreement to fight "fair," but it is not impossible (see below). Regardless of whether the agreement is honored, though, it explicitly proposes to do violence as a fight.

The processes I describe are best understood as practices rather than rules, yet deviations from the routine could take on a normative character (see Garfinkel 1967; Heritage 1984). An instructive incident occurred during the second week of my fieldwork. On Christmas night, 1999, I had been play fighting in the front yard at a house party with Justin and his young brother, Joe. After Justin and I resumed a casual conversation with several other partygoers Joe went inside the house. A few minutes later, as I stood on the front porch, Joe charged back outside, tackling me from behind. My right forearm snapped when we landed. After struggling free, I ran inside and called for an ambulance. When I came home from the hospital two days later (following surgery), Joe called me to apologize and offered to drive me around if I was incapable of driving myself.

For several weeks the incident was a frequent topic of conversation among the core sample members. Opinion was divided over whether Joe had unjustly attacked me or accidentally injured me. A few of Joe's friends suggested that I wait until my injuries healed and retaliate. Tellingly, no one ever called the incident a fight, instead saying, "He basically just manhandled you" (Raj) and describing it as "like an all-out, brutal attack" (Rick). Members 
might express some degree of disapproval about such violations of the routine practices of fair fighting, but they were generally left to the principal actors to resolve. Members treated these violations of the routine practices as unfortunate, but occasional and predictable occurrences in contexts where people drink heavily, sometimes use drugs, and often actively stir up trouble and action (Goffman 1967).

\section{Looking for Trouble}

In Chad's and Andy's middle and high school fights above (cases \#76 and 33), the instigators seem to have been "looking for trouble." During adolescence, schools did much of the work of organizing the conditions for finding trouble, in large part by imposing common daily routines and dense networks of long-term relationships on hundreds of status-conscious peers (notably, conditions shared by correctional facilities, certain other "total"/"near-total" institutions, and some impoverished neighborhoods). After high school, though, the social structure supporting such adolescent violence vanished.

During late youth, most members held a complicated, ambivalent attitude toward fighting. Many sought out fights "for fun;" that is, to experience the thrills, prestige, and other symbolic rewards of exciting, fateful action (Collins 2008; Goffman 1967; Katz 1988; see also Geertz 1973; Lyng 1990; Schinkel 2010). As Leigh once put it, when she and her friends went out partying they had an unspoken agreement that "we were gonna go out and get in a fight."11

Yet they considered it juvenile and morally offensive to openly incite violence for its own sake, especially against involuntary opponents. Complicating the search for trouble, they

\footnotetext{
${ }^{11}$ Fieldnote Interview (April 26, 2003).
} 
preferred to fight strangers rather than friends. Fights between friends often resulted in hurt feelings and emotional apologies. They occasionally involved uncomfortable stretches of crying (as happened after "the burrito incident," Case \#60, above). Fights with strangers would be onetime affairs, no-strings-attached. But trying to fight with strangers poses special practical problems, namely, selecting opponents, finding something to fight over, and coming to feel the fight is authentically motivated by conflict.

How, then, to find trouble without forcing it? One attractive solution was to go out carousing, or partying (Tomsen 1997; Winlow and Hall 2006). ${ }^{12}$ Alcohol was an important part of the process, though not by a strictly chemical mechanism. As 21-year old Tim related, he and his friends considered drinking and fighting practically a single unit of activity: "I don't know how many times I've heard the phrase, 'Let's get drunk and go fuck with somebody.", Above and beyond any physiological effects, fighters considered drunkenness an indicator of their own, their teammates', and strangers' openness to fighting. My sample members believed that alcohol facilitated violence, and their actions often confirmed this belief, a self-fulfilling prophecy that subsumes chemical causation (see McAndrew and Edgerton 1969; Orcutt 1978).

Just as important were the social dynamics of the situations in which they drank. Carousing is a special kind of situation, described in sociological detail by Collins (2008, 242 281). It includes useful ingredients for trying to get into physical fights, but also for finding sex partners, scoring drugs, drinking to excess, destroying things, and quarrelling with strangers. Carousing shares several goals in common with fighting, including the projects of creating action, constructing a "situational elite," and making good stories (Collins 2008; Goffman 1967;

\footnotetext{
${ }^{12}$ Of 122 fights, $44(34 \%)$ were in carousing contexts. There were also 27 near fights, 19 jumpings, 12 individual attacks, 4 cases of gunfire, and 4 additional cases of showing a gun.
} 
Jackson-Jacobs 2004a). It consists of large gatherings in which people create collective action and disorder in a spirit of mischievous anomie. People pack together densely and disregard ordinary restraints. Crowds dance, joke and laugh, talk openly with strangers nearby, and put their hands on each other with various intentions. Large audiences watch small clusters of partiers making interesting spectacles, whether they are fighting, dancing like fools, sexually groping each other, or just lying in their own vomit.

Wild as such scenes could get, fights did not simply erupt or break out randomly, as colloquialisms and popular imagery suggest. Very rarely did instigators approach targets and immediately throw a punch. Nor did they walk up and propose to fight cold. Like picking up a sex partner, it took more finesse than that. Instead, instigators would provocatively invite potential opponents to collaborate in conflict. Invitations took the form of subtle variations on ordinary situational behavior such as touching, rude comments, and eye contact:

\section{Case \#13. Leigh and Jennifer Fight at Nacho's Tacos}

Fieldnote Interview (April 26, 2003): Jennifer kept saying that these two girls were looking at us. And so she was totally talking shit to them. Like, "What the fuck are you looking at, bitch?" ... she went over to their table and started punching one of the girls... I was trying to break it up, but I guess the only thing you can do is punch people in the face. [Laughing.] At some point though it turned into just wanting to kick their asses and hurt them. So we were fighting and I was like on top of this girl punching her and holding her down on the table.

The "accidental" bump was used at least 11 times in my dataset (see Katz 1988, chap. 3).

Such invitations were often ambiguous enough to ignore at little cost, should the target not be open to a fight:

Case \#190. TJ Bumps a Guy at Sharky's

Fieldnote Interview (July 16, 2000): TJ told me he had bumped into someone at Sharky's "kinda hard," but tried to make it seem unclear whether or not he meant to hurt him or was just trying to get by. A couple steps later the guy turned around 
and was looking back at TJ. So TJ gave him a "come on outside" kind of smile. He never came out though.

Moreover, the line between ordinary behavior and invitations to trouble was fine enough to be a source of misunderstanding in either direction. That is, ordinary behavior could be interpreted as intentional trouble, and intentional troublemaking could go unnoticed:

Case \#197. Stranger Postures Aggressively.

Fieldnote (September 1, 2001): After I returned from the bathroom, Gilbert and TJ told me that some guy had just tried to start a fight with me. They told me that I had bumped into him accidentally and he had turned around and stared at me aggressively. They said he then followed me for a few steps and swayed his shoulders about as if to suggest that there was some trouble between us. When I continued on, unaware, he turned around.

Such attempts were oftentimes admittedly clumsy. Gang identity, by contrast, provides highly routinized methods for solving the problem of creating interpersonal challenges by justifying fights on grounds of turf and gang membership. In some neighborhoods, aggressively demanding to know a stranger's gang affiliation is a highly scripted routine for establishing interpersonal conflict, potentially leading either to competitive fights or unilateral attacks (Decker and van Winkle 1996; Garot 2007a; Katz 1988, chap. 4; Sanders 1994). Southern California inner city youths have developed the unambiguous and elegantly parsimonious challenge, "Where you from" (Garot 2007a). Members of social ecologies with a recognizable gang presence immediately recognize, in the first turn of talk, its threatening implications. While the ensuing fights may follow the general process I outline, gang identity provides distinctive rituals and resources for achieving the ingredients of a fight (Garot 2007a, 2010).

In carousing contexts, the invitations fail more often than not. As TJ describes below, one night Brian made "a good effort" on behalf of his group of friends, rather indiscriminately 
provoking a series of strangers, most of who declined to escalate. Finally, when a group of

"really big guys" showed up, Brian successfully antagonized them and got himself and his team beaten up:

\section{Case \#101. Rick, Brian, TJ, and Joe Get Themselves Jumped}

TJ: A couple times some people would be leaving, and so [Brian]'d just go stand in front of them and just stare at them. And they would just have to squeeze by him. That was the most subtle thing he did.... these other guys were leaving.... He just starts picking up rocks and throwing them at them.... But they just ignored him.... [Later on] all these big guys were angry because they wanted to beat someone up.... And Brian's just standing there staring at them. And this big black guy starts walking toward him and said, "What's your problem, dude?" And Brian takes a look at him, and takes a drag of his cigarette and flicks it at him.... then he said, "I don't know, man. It looks like you're the one that's trippin'." And the guy was like, "Oooh! That's it!" and ran over at him.

In one common routine, instigators exploit the carousing situation in an ironic way. The instigator initiates a conflict by treating targets as responsible for creating situational disorderconveniently, the same disorder endemic to carousing scenes. One party accuses the other of wrongdoing, orders the other to take remedial action, or demands an explanation. To get angry, disputants drop the substantive matter and begin quarreling about ritual or remedial matters (Goffman 1971) - that is, about how the other is arguing. A typical example:

\section{Case \#1. Brawl at the Midtown Club}

Charlie: This frat boy bumped into his girlfriend and tripped. She spilled her beer on one of my friends. Then he told one of my friends to apologize. And my friend wouldn't do it. So they started to argue.

What begins as disingenuous indignation might easily become genuine anger over a few turns of "talking shit." A case described by Tim, a member of a skinhead friendship group, illustrates this point. He and two friends had been hanging out for a couple hours at Sharky's (a popular dive bar) when three "frat boy faggots" (i.e., young men with a "college" look) came in 
and started getting drunk and playing around in a rowdy way, as carousers do:

\section{Case \#10. Tim at Sharky's}

Tim: And they knock one of these big, lit-up Coors signs off the wall, right? And I'm all drunk, so I'm like, you know, this'll be funny. I go, "Hang that sign back up." The guy's like, "Fuck you, I didn’t knock it off." ... I go, "Was it your friend? ... Then it was you. Hang it the fuck back up." And he goes, "Fuck you, I'm not fucking hanging anything up.... You fucking faggot." ... I got in his face, said, "We're going outside. I'm gonna beat your fucking ass. ” Out of nowhere his friend...comes running up and got me in a chokehold. Boom! Hits me. (emphasis added)

Many disputes had such a bootstrapped character. In order to fight, members had to creatively find a problem with a cooperative stranger — one that would make an authentic reason to fight. Thus, the reason to find a conflict is to start a fight, but once the conflict is found, it becomes the reason to fight.

\section{Transcending the Ordinary Fear of Using Violence}

There is an important moment in the process of fighting, but it is not always obvious. One of the disputants must attack first. Sociologists and popular culture tend to treat this moment as unproblematic, but getting the violence started can be a serious challenge, even for highly motivated actors (Collins 2008).

In certain cases, even after the disputants have agreed to do battle, even when a crowd is circled and cheering, they may still not fight, at least not right away. It can take several minutes for someone to throw a punch and start the fight. To illustrate, a fight after school between Drake and a classmate, with an audience watching:

Case \#31. Drake's Showdown 
Drake: ....there was a whole bunch of people... A whole crowd.

Curtis: Did you guys talk shit to each other?

Drake: Not really, we kind of stood there for a good fifteen minutes just waiting for somebody to make the first move.

Then, in an instant, everything changes. A first punch is thrown and both fighters "let their hands go," as boxers say, the punches flying at a frantic rate. What has happened?

The emotions in fighting are more complicated than one might imagine. People do not use violence randomly, nor simply when emotions erupt and they "lose control," as is sometimes presumed (Gottfredson and Hirschi 1990; Wilson and Herrnstein 1985). Anger or rage is common, but not necessary (contrast with Berkowitz 1989; Dollard et al. 1939; Freud 1959). Fear or tension is universal, though not in the way one might expect. As Collins (2008) observed of violent acts ranging from fistfights to riots and military combat, virtually everyone feels considerable "confrontational tension/fear" when preparing to actually use violence, regardless of culture or individual personality (except, perhaps, incompetent social actors like small children, the extremely drunk, or the severely mentally ill). At times, people may be deterred by the fear of injury or punishment. However, above and beyond injury and punishment, one basis for tension/fear is universal: Ordinary interaction involves a fundamental, structural preference for nonviolence. ${ }^{13}$ That is, violence requires special circumstances, procedures, and justifications to remove the moment from the ordinary (Collins 2008).

Based on my dataset, one emotional process is common to all full-blown, serious fights: transcending the ordinary tension/fear of using violence in a "last chance" moment of

\footnotetext{
${ }^{13}$ In micro-sociology “preference organization” refers to a structural relationship between alternative courses of action, e.g. nonviolence vs. violence; agreement vs. disagreement (Sacks 1987); and informal vs. formal social control (Emerson 1981).
} 
extraordinary urgency. It is not only a matter of achieving the right "definition of the situation" (Athens 1997, 2005; Luckenbill 1977; Mead 1932/1964); it is also a matter of undergoing a radical shift in one's sensual, emotional appreciation of what is happening (Katz 1988, 1999). Opponents must provoke in one another an immediate fight-or-flight crisis, often in collaboration with an encouraging audience. Then, to initiate an attack right now, one of them must conquer fear by perceiving the immediate present as posing an urgent, "last chance" requirement to use violence - that is, the last chance to maintain a strategic advantage, to seize a thrilling opportunity, or to avoid moral failure. The experience is always some combination of fear, excitement, and/or anger, oftentimes mixed with a sense of obligation to teammates or audiences.

\section{Meeting in Showdowns}

Compared to other fights, the process of transcending fear is unusually drawn out in time, and is thus easiest to see in the variety of fights I refer to as "showdowns." In my dataset, all showdowns were transacted between teenagers, usually around high school campuses. As in traditional duels, the opponents got into a dispute in one situation but negotiated some other time and place to fight, frequently after school (Collins 2008). Oftentimes, however, the disputants have lost any animating anger by the time they meet. A distinctive quality of showdown-fights, then, is that opponents must work to revive the conflict or provoke a new one.

When they meet, disputants typically find they have an obligation to their audience to fight. During a group interview, Joe (a fighter) and Rick (a classmate at the time) described the audience's role in sustaining a dispute over several hours of a school day. One student, Brandon, had been "picking on" a classmate in physical education class that morning when Joe voiced his 
disapproval. "The wall" that Rick mentions below was the school's traditional spot for illicit activities such as fighting and smoking cigarettes:

\section{Case \#35. Joe vs. Brandon}

Joe: ... it was just a smell there in the locker room that something was gonna happen. [Everyone laughs.] "After school" ...

Rick: "After school!" Meet me at "the wall”!' [Everyone laughs.]

Joe: So, it was, you know, set in stone. It was granted ... eventually it spreads ... like a nuclear explosion. There's no way of getting around it-

Rick: Everyone knew you were gonna fight so you just had to ...

Joe: By lunch time, everyone knew. I mean, people who didn't even know me knew.

Rick: It was like, "I heard Joe Nash is gonna fight Brandon James at 'the wall!" [Everyone laughs.]

Joe: And then my brother [Justin] ... he's always friends with Steve and all the so-called popular people at the time. So, you know, everybody's talking shit to him [Brandon], "Joe is gonna beat your ass!" ... So, you know, the day ended and we went over to "the wall"... And, of course, there's masses of people...

The original "reason" for the fight may no longer matter. Instead, upon meeting, the new challenge is to motivate oneself or one's opponent to throw the first punch. Oftentimes, the audience itself pressures an opponent into a "last chance" crisis moment: Take the fateful step of throwing a punch now or risk losing one's nerve, backing down, and suffering humiliation in front of everyone.

An example from my own experience: When I was 15, my friend Bert had just moved to a new neighborhood across town. Soon afterward he went out vandalizing property and threw a wad of wet biscuit dough on a big white Cadillac, owned by a 17 year old, Bennie. Bennie later confronted Bert, who blamed me. I was willing to fight Bennie, mainly in the interest of developing toughness and a good story, so I let him believe I was the culprit. Since we lived in different neighborhoods and went to different schools, Bert arranged for us to meet a few days later at a place they called "the pit." 
Importantly, when we faced off, Bennie never mentioned his car or the wet biscuit dough. Instead he tried to provoke a new reason to fight based on immediate situational resources, insulting, shoving, and challenging me. In the end, however, the situation became acutely more urgent for Bennie, largely because his friends were taunting him:

\section{Case \#34. Bennie and I Have a Showdown}

Retrospective Observation: [Bennie] said, "What's up?" [A proposal to fight.] He accused me of being scared... I told him repeatedly, "Make the first move, it's your fight." After a few minutes his friends started to taunt him. Bennie shoved me. I just looked at him. He shoved me twice more... After a few seconds he punched me in the left cheek.

Once Bennie actually punched me, the crisis of indecision was resolved and replaced with another: We became entangled in the characteristic urgency of back-and-forth punching and wrestling. Someone is attacking, so one must fight or flee right now.

Urgency

Regardless of how a fight begins, the moments of attacking have a similar tone. Once the situation becomes urgent, fighters come to feel possessed by forces beyond their conscious control (though, as I argue, their conduct is still demonstrably socially organized). They describe the feeling in various biological and primal terms: "It was just like instinct. You know, like that rush" (Scott, Case \#28; emphasis added). The "flight" impulse in fight-or-flight urgency may be overcome through any of several competing emotional interpretations of the situation, all of them framing the immediate moment as a last chance for action. Ironically, extreme fear is one pathway. A fighter may strike first in a self-defensive panic, anticipating that, if he does not, the other will (see Case \#76, above). 
When fighters recounted anger in my data, their accounts also suggested tinges of exhilaration. In the next case, Will, Bob, and a few friends were drinking and commiserating at a low-rent downtown nightclub after Will's mother and Bob's sister had died in the same week. They got into a conversation with the singer of a punk rock band playing at the club. As Will explained, the singer was acting "obnoxious" and "asking stupid questions" about the deceased. An argument ensued, and Will walked outside with his antagonist following a few steps behind. I asked Will, "What were you feeling at that moment, like emotionally?"

\section{Case \#103. Will and Steve's Post-Funeral Brawl}

Will: Just like adrenaline rush-like, "Make the wrong move, fucker." ... I was angry.... and I was just ready to fight... he grabbed my shirt and he started ripping my shirt. And I started hittin' him in the nose. (emphasis added)

As Will's comment indicates, some kind of "wrong move"-in my terms, one provoking a last chance crisis — is necessary to actually attack, even when fighters have already agreed and are, in a broader sense, "ready to fight." Provocative gestures like pushing, poking, or grabbing and ripping clothes are of special practical value because they are not yet full-blown, urgent violence (and thus easier to perform [see Collins 2008]) but they are likely to provoke a violent response from the target.

Here there is a strong element of collaboration. Urgency, and thus the emotional impetus to strike, cannot be summoned by the individual alone. Through a series of escalating moves and countermoves, however, antagonists can reorganize the situation so as to require one of them to initiate violence now. Violence and violent emotions are self-escalating and irreducibly collective phenomena, developing above and "beyond anything anyone...could intend or bring about" alone (King 1995, 639).

In group fights, the collective nature of the event itself may encourage the sense that 
immediate violent action is required, inspiring additional combatants to "jump in." Group

combatants often conquer fear by acting on a sense of duty, recognizing that teammates are

overmatched and that succumbing to fear would reveal cowardice. In the following fight-turnedjumping at a house party, Chad was on the ground being kicked by a group of young men when

Will, Powel, Steve, Bob, Justin, and Rick jumped in:

Case \#98. Brawl at Steve, Jordan, and Jake's Party

Will: And all of a sudden we just see all these people rushing in there... I just started jumping in the crowd.... I was scared.... It was a huge crowd of people. You know if you get in there with your friends you're gonna get your ass kicked anyway. You just go ahead and do it anyway.... I was kinda' like pounding, swinging. You know, a lot of fear, it was really scary. And a lot of adrenaline. And there's a part of you that doesn't want to do it. The part that wants to keep yourself safe. (emphasis added)

For those who do not flee (and people often do), such fights may also entice by promising strong thrills, particularly those of demonstrating character and solidarity (Goffman 1967). Thus, fighters sometimes overcome fear by appreciating the fight as a rare and precious opportunity. As TJ explained above (Case \#101), he and his friends had spent the night unsuccessfully looking for trouble. When it arrived, TJ focused not on the danger but the thrill. Seeing that Rick and Brian were being attacked by a crowd of opponents, TJ ran toward them:

\section{Case \#101. Rick, Brian, TJ, and Joe Get Themselves Jumped}

TJ: It wasn't that I was afraid. I think I was actually kind of excited. Like, “Okay, it's really gonna happen!' I didn't think about the fact that we were probably going to get annihilated. (emphasis added)

It may have various emotional overtones but the "it's-really-gonna-happen" sentiment is felt in all fights. When the fight-proper is just about to begin, when the first bell signals a boxer to step out of his corner, or when a skydiver takes the last step out of an airplane, the actor experiences 
the same recognition that one is about to depart the world-as-ordinarily-known and enter the realm of extraordinary urgency (Lyng 1990; Wacquant 2004).

Even after initiating violence, however, a proper fight is still a contingent matter. What happens during the violence remains a critical determinant of whether and for how long an interaction remains a fight or becomes something else (e.g., a beating, jumping, or shooting). As Katz (1988) and others (Foucault 1977; Girard 1977) have noted, violence has a sacrificial character, particularly when motivated by rage. Should one disputant treat another as an offender and punish him in the name of justice, then the interaction may take on the character of "righteous slaughter" rather than a fight (Katz 1988). Fights are also motivated by a sacrificial sentiment. However, the sacrifice takes a special form. In order to fight, one must sacrifice oneself.

\section{Using Practices of Competitive Violence}

In ordinary interaction one has the sense of directing one's own conduct, of being "in control." In crisis situations people feel "carried away" by uncontrolled emotions; the body seems possessed by primal forces as if it is acting of its own accord. Yet people continue to act in socially sensitive, symbolically meaningful ways. The surprising degree of social order in fights challenges the usual perspective that violence is purely psychological and impulse-driven. Like other "techniques of the body" — dancing, swimming, playing piano-ways of fighting are socially learned, practiced, and interpreted, making them amenable to sociological analysis (Mauss 1933/1973; Schutz and Luckman 1973, 105-111; Sudnow 1978).

Much of the work of creating a fight is to establish mutuality. It begins with arguing and 
continues in combat. To construct violence as a fight it must be performed in a competitive fashion. Fighters use various practical techniques to sustain the sense of competition, such as making targets of their own bodies, fighting back-and-forth, and stopping upon victory.

\section{Making a Target of One's Own Body}

To avert one-sided violence, it is common for opponents to directly invite attack, especially at the start of the fight, often accompanied by further provocation. Andy's showdown-style fight with Hank, introduced above, provides a particularly explicit illustration. They had just squared off after school. I asked Andy what he was saying:

Case \#33. Andy vs. The Football Player

Andy: Just like, “Are you gonna swing, bitch? Are you gonna swing?" He swung and I ducked it.... he swung again and I ducked it again. And then he said, "Quit moving so I can hit you." And I did it. And he hit me right in the nose and broke it. (emphasis added)

Andy not only challenged Hank to punch first; he actually collaborated with him to make sure the punch landed. As Simmel (1955) noted, even in conflict, antagonists share a common focus on what is under dispute and how to proceed with conflict and, thus, must engage in varying degrees and forms of cooperation (see Luckenbill 1981; compare to Athens 2005).

Fighters make vulnerable targets of their own bodies in other ways. They may stand within arm's reach and slap, point, or poke at each other. When employed at close range, the provocative "take your best shot" posture (arms raised, feet planted to the sides, torso facing the opponent) makes offense impractical for oneself but easy for one's opponent (in an orthodox boxing stance, the right foot and shoulder are behind the left, and the hands are kept close to the 
torso or head). Fighters "get in each other's faces" literally and figuratively, simultaneously

provoking and making themselves vulnerable. Just as ritual insults replace the initial substantive disputes as the motivation to continue disputing, and audience gaze may then replace the original dispute as the present concern, so too does the provocative bodily interaction, once again, recast and sustain the motivation to continue toward a fight.

\section{Back-and-Forth Violence}

Several phrases capture the symmetrical quality of unarmed, competitive violence: "hand-tohand," "toe-to-toe," "face-to-face." As boxers know well, whenever one throws a punch one also leaves an opening for counter-attack. Thus fights rarely end without some give-and-take. In fact, fighters do not just encourage some degree of back-and-forth violence; many of them relish it. There is little competitive satisfaction in beating an unskilled or unwilling opponent (though there may be other satisfactions). A "good fight" means overcoming vigorous resistance. Thus, Kenny recounted disappointment when one opponent failed to put up serious opposition:

\section{Case \#49. Kenny vs. "Hippie”}

Kenny: He was like, "You want to fight?". . he grabbed onto me. And we, like, rolled down the hill a little bit. And I just started punching him in the head ... He just stopped doing anything pretty much when I hit him.... I stopped for a little. And he's like, "Uuuh, that's enough." And then he just fucking laid down. And I left....

Curtis: So was it a good fight?

Kenny: I thought it sucked. I was pretty disappointed 'cause first he grabbed me and, like - he was bigger than me and had more leverage and strength, so that I thought I was gonna have to wrestle with him for a little while. But I just hit him in the face right off and he didn't do much after that.

Likewise, taking a beating need not be disappointing (Jackson-Jacobs 2004a). As in 
competitive sports, there is satisfaction in "going down swinging." TJ told me of the losing battle mentioned above (Case \#101), "I think it was good that we fought those guys. Because now I'm not afraid to fight really big guys anymore, because they didn't really hurt me."

For most practitioners, punching the face is not a devastating technique, only rarely incapacitating the target. Though it may feel as if the punches fly automatically, the practice and aesthetic sensuality of punching — the automaticity itself — is socially learned. A number of more injurious attacks could be deployed with similar technical ease, especially eye gouging, but they rarely are. In the nineteenth and early twentieth centuries, eye gouging was, in fact, how many Americans fought (Gorn 1985). The relative safety of contemporary fighting is based both on culturally-, historically-specific practices, and also on a considerable degree of trust, solidarity, and restraint between opponents (Collins 2008; see also Simmel 1905/1955).

Punching the face does, however, produce a symbolic crisis and an immediate, humiliating provocation (e.g., see Anderson 1999, 82). The face is the primary site of perception and where the self is most publicly exposed in social interaction. Striking the face assaults the opponent's senses and demands attention. Thus contemporary fighters rarely try to inflict maximum harm; they try to win in a symbolically meaningful, social ritual of violent competition.

Furthermore, back-and-forth, hand-to-hand fighting creates the conditions for an allconsuming "zone” of creative physical artistry, what Csíkszentmihályi (1990) called "flow." The immediate present requires total concentration. There is little time to consciously strategize or reflect on the opponent's range of potential moves. Nonetheless, one's body executes extraordinary feats of athleticism, and does so in ways that have strategic and symbolic significance. 
Below, Raj savors the memory of punching a stranger in the face. Notice the practical details of his performance. He uses the more martially effective technique first (kneeing the man in the groin), setting up the less effective but more aesthetically satisfying technique. Raj does not just savor inflicting harm; he appreciates the thrilling bodily sense of self and other experienced through the "perfect" punch — the "power" of his knuckles, deltoids, and pectorals reflected off his opponent's flesh and skull:

Case \#21. Raj Socks a Stranger in Troy

Fieldnote Interview (September 16, 2001): A stranger was bumping into and staring at Raj so he asked if he "had a problem or something?" The man then sucker punched Raj. As he described it, he "just wanted immediate revenge." So he "racked him in the nuts" with his knee right away. The guy bent down, holding his groin. Raj "just jacked him in the head so hard." The punch "was perfect," he declared. The guy "just went down right then."... It felt "so solid." He ran one palm along the knuckles of his other hand. All of his knuckles "landed so flat." It landed "right here" where his jaw met his ear. From that angle, Raj recalled, "I could feel my pectorals and my deltoids working together. Just everything connected all at once." He described how he followed through with the punch and how he could feel the man's flesh "resisting the power of the punch....But it was no match for the power," he concluded. "It was just so satisfying." (emphasis added)

Stopping upon Victory

There are four possible ways for a fight to end (compare to Athens 2005): A third party "breaks it up," both sides negotiate a retreat upon reaching a stalemate or draw, one side stops upon establishing victory, or the violence begins to take another shape (e.g., a beating, jumping, or shooting). When one side gains an advantage, it becomes possible to pursue a unilateral attack, but to do so means ending the "fight" (if not the violence). To sustain the sense of competitive violence the winning fighter must stop attacking shortly after the loser admits defeat, either 
verbally or with a tacit gesture of submission. In the following cases, winning fighters accepted the admission of defeat:

Case \#31. Drake's Showdown

Drake: I was punching his face for a while... And then he was like, "That's it. I quit! I quit!” And I'm like, “All right, cool.” I just got up.

Case \#33. Brady \& Anthony Showdown

Retrospective Observation: Brady kicked [Anthony]...knocking him down. Brady pursued him for several steps, but Anthony scooted away...holding his hand up to signal defeat.

There is, however, no clear cutoff for deciding what constitutes stopping "soon enough," so violence toward the end of a fight often risks becoming one-sided.

\section{Transitions to Other Violence}

In fact, winners and coalition members do sometimes abandon competition and instead attack someone well beyond establishing "victory.” By my coding, approximately 16\% (21 out of 122) of the fights in my dataset transformed into some form of unilateral violence. There are several pathways out of the fight-proper and into unilateral violence, all responding to the situation's transforming meaning and emergent possibilities. People infatuated with guns sometimes view fights as opportunities to brandish or discharge them (no one in my data was ever shot in a fight situation). At other times, simply “winning” wasn't dramatic enough to demonstrate just how offensively the target had acted. In others, teammates opted for the thrill of a ritual beating over watching a fight.

In my dataset, individual attackers who continued past victory followed the process of 
enraged "righteous slaughter," as described by Katz (1988). Viewing targets as having humiliated them, they attacked in a spirit of sacrificial punishment (Foucault 1977, chap. 1). During one group fight several men had chased Rick, frightening him into running away in a panic - a potentially serious humiliation, especially since he was an experienced martial artist and military service member (Case \#101; see also above). Moreover, they had begun to jump his teammates. Seeking redemption, Rick hid behind a tree in order to ambush one of his pursuers. He savaged the man in a rage, beating and knifing him in punitive spirit:

\section{Case \#101. Rick, Brian, TJ, and Joe Get Themselves Jumped}

Rick: I had the knife in my fist, and I just used it to slash his arms.... he just started cowering. He was screaming and shit. But I was like, "I'm gonna teach this guy a lesson about thinking with testosterone and not handling his alcohol."

Rick [in a second interview, on location]: He fell down right here [Rick pointed dominantly to a spot on the ground, clearly excited]. And that's when I was like, "Oooh, I'm fuckin' gonna waste this dude right now. This dude's fucking dead."

When one member gets into a fight, the rest of his partisans may find the prospect of collective effervescence (Durkheim 1912/1995) and dramatizing membership more compelling than the excitement of spectatorship. In contrast to individual beatings, attackers in group beatings were usually more exuberant than enraged (see Anderson 1999; Buford 1990; Collins 2008; King 1995; Sanders 1994). The violent sacrifice was made less in the name of punishment than group solidarity (Erikson 1966).

In the following case, Powel was at a house party when a stranger shoved a friend of his. Powel punched the young man in the face, and the rest of his friends "jumped in." He described a sense of power and domination, but also the transcendent intoxication of membership:

Case \#96. Jumping at Jeremy O'Reilly's Party

Powel: [We] just started jumping this guy. And that was as a group. And it just 
felt like power, you know. "We don't have to stand for nothing!" You know, "We stand as a group! Tear people down!"... And I think that really glued the whole mess of us. (emphasis added)

In Powel's jumping there was only a minimal semblance of a competitive fight beforehand. In other cases, groups of third parties only chose to jump in once a fight was well underway. Hernandez recounted a situation in which the initial one-on-one "fair" fight ended with the loser running away, at which point the winner's coalition gave chase. Hernandez and his friends were at a large house party when "a bunch of Crips" (a youth street gang) started an argument over a marijuana joint they were all sharing, a dispute Hernandez's crew was only too ready to escalate:

\section{Case \#97. Hernandez's Crew Jumps a Crip}

Hernandez: ... they started talking shit. And [Wayne] was all, "We could take it to the street." ... The rest of the Crips tried to rush up on my buddy, Wayne. And that's when the rest of us just walked up and we're like, "What? Let them go oneon-one." So they're going one-on-one, they're hitting each other ... next thing I know, dude, the dude gets up and starts running off... And we run after this dude... That was when like five of us just jumped him, dude.... Punching him on the head, kicking him in the face.... I had blood all over my shoes, dude.... I never have really fucking kicked somebody that hard.

At first glance, such jumpings may appear reminiscent of Jack London's (1903) depiction of wolf packs automatically attacking the fallen losers of one-on-one fights in The Call of the Wild. But, as Mead (1962) noted, unlike the automaticity of animal aggression, techniques of human violence are always meaningful, symbolic action. Note that Hernandez's group did not descend upon the man as soon as he fell down. By running away the losing fighter effectively ended the "fight" (and, for the victor's team, invalidated the "one-on-one" agreement), creating a spatial and narrative break in the situation. Hernandez's group seized the opportunity to recast it as a jumping. The implicit narrative conclusion to the new situation (a "chase") was for the pursuers 
to beat their prey once caught.

Audiences shape the violence whenever they are present. They may support a one-on-one fight by circling and watching, turn it into a group fight by exchanging blows with other partisans, supplant it with a jumping by swarming upon a weaker target, or attempt to prevent the violence from escalating. Though it may not always be obvious, the combatants are not the only social actors with a hand in constructing a fight.

\section{Discussion}

Academic and media attention are disproportionately directed to the most socially distressing, easily defined, and extreme forms of violence. Fights (and fighters), however, do not fit the standard imagery of what violence looks like or how it works. Fights are not "pure" violence, as people usually think of it; oftentimes there are no clear victims or perpetrators, it may be difficult to assign blame, and, indeed, both "sides" may claim virtuous justification (e.g., defense of self, others, or "The Good"; see Katz 1988, chap. 1).

Social scientific explanations frequently assume preexisting, independent "reasons" for conflict, or they describe violence as the triumph of "out of control" psychological impulses over civility (e.g., Berkowitz 1989; Black 1983, 1998; Dollard et al. 1939; Freud 1959, 1930/1989; Gottfredson and Hirschi 1990; Wilson and Herrnstein 1985). Yet what is most striking about the process is the degree to which combatants harness and exploit social resources to achieve a fight, and to which fighters remain socially sensitive even in moments of extraordinary duress.

Looking closely at the details of fight interactions, it becomes clear that the fight and the reasons for conflict are not independent. The initial incentives to pursue a fight are diverse in 
their specifics, including the thrills of demonstrating "strong character," establishing solidarity, and achieving narrative payoff (see Collins 2008; Goffman 1967; Jackson-Jacobs 2004a). In fact, by the time they actually start throwing punches, the opponents may remain only dimly cognizant of the original reasons for the conflict. Instead, the entire fight interaction is a project of creating, renewing, and attributing its own reasons for existence. One provokes and subjects oneself to situationally emergent, collaboratively constructed motivating challenges: an "accidental" bump, a gesture interpreted to be insult, audience pressure, the strategic positioning of one's body relative to the opponent. Thus, the fight interaction always has something of a tautological character (and herein lies much of its charm for those who start fights): Constructing a fight is a process of actively invoking justifications for violence, and then feeling authentically motivated by them.

The immediate social reality of the fight is its interactional organization. Yet it is important not to overstate the degree of organization in fighting. No universal law dictates that once begun anyone must complete or sustain a fight. Fights may always "turn into" something else-indeed, they must. Interaction always requires creative, spontaneous engagement with the details of one's immediate situation. Like social life generally, violent situations can never be completely scripted.

If there is no guarantee that what starts as a fight will end that way, then what is the point of identifying the last moments of the fight, investigating fights at all? Isn't the practical construction of a fight simply a matter of definitions? In fact, explaining how people define things is part of explaining why they do them, that is, when they use knowledge of the definition as a "recipe," or practical guide to action (Schutz 1966; Schutz and Luckman 1973). In MacIver's (1942) terms, such phenomena involve an element of "teleological causation" 
(Gasking 1955; Schinkel 2010). For instance, part of the reason to stop upon victory is to intentionally enact violence as a fight. The fighter is specifically trying not to bully, beat, or otherwise attack unilaterally; he is trying to be a "competitive winner" rather than "sadistic predator." What makes this feat sociologically remarkable is that it is virtually impossible to consciously reflect on one's behavior during a heated violent exchange, demonstrating that, contra conventional wisdom, symbolic action may be just as automatic as psychological impulse.

At this point it is apt to return to Mead's (1934/1962) classic account of two dogs fighting as a "conversation of gestures," that is, bodily communication enacted without reflective deliberation. Human fights are also conversations of gestures, but there is an important difference between the two. For the dogs, each move is an instinctive response to that of the other. There is no meaning, only stimulus and impulsive response. For humans, although "a great deal of [fighting] has to be without deliberation," it is nevertheless socially sensitive in multiple ways (Mead 1934/1962,43). Symbolically, one is constantly attentive to the meaning of the immediate moment, both for present and future interpretations. Strategically, the fighter represents to himself his own and his opponent's range of moves. One "may deliberately feint," intending to "call out" in the other an offensive gesture in order to then dodge and deliver the decisive counterpunch (Mead 1934/1962, 44; see also Raymond 2009). From this perspective, then, there is a fundamentally social basis for the "ways of the fist" (see Sudnow 1976). Even when it appears we have found the animalistic within human behavior — perhaps, especially then-we may, in fact, have only discovered that social sensitivity runs much deeper than we previously imagined. 


\section{References}

Anderson, Elijah. 1999. Code of the Street. New York: W. W. Norton.

Athens, Lonnie. 1997. Violent Criminal Acts and Actors Revisited. Champaign, IL: University of Illinois Press.

Athens, Lonnie. 2005. Violent Encounters: Violent Engagements, Skirmishes, and Tiffs. Journal of Contemporary Ethnography 34 (6): 631-678.

Baron, Stephen. 1997. Canadian Male Street Skinheads: Street Gang or Street Terrorists? Canadian Review of Sociology and Anthropology 34: 125-155.

Becker, Howard. 1953. Becoming a Marihuana User. American Journal of Sociology 59: 235242.

Berkowitz, Leonard. 1989. The Frustration-Aggression Hypothesis: Examination and Reformulation. Psychological Bulletin 106: 59-73.

Black, Donald. 1983. Crime as Social Control. American Sociological Review 48(1): 34-45.

Black, Donald. 1998. The Social Structure of Right and Wrong. New York: Academic Press. 
Blumer, Herbert. 1969. Symbolic Interactionism. Englewood Cliffs, NJ: Prentice-Hall.

Bourdieu, Pierre. 1984. Distinction: A Social Critique of the Judgment of Taste. Cambridge, MA: Harvard University Press.

Buford, Bill. 1990. Among the Thugs: The Experience, and the Seduction, of Crowd Violence. New York: W. W. Norton \& Company.

Centers for Disease Control. 2012. "Youth Risk Behavior Surveillance-United States, 2011." Morbidity and Mortality Weekly Report 61 (SS-4). Atlanta, GA: U.S. Department of Health and Human Services.

Cheng, Tina, Donald Schwarz, Ruth Brenner, Joseph Wright, Cheryl Fields, and Regina O’Donnell. 2003. Adolescent Assault Injury: Risk and Protective Factors and Locations of Contact for Intervention. Pediatrics 112(4):931-938.

Collins, Randall. 2008. Violent Conflict: A Micro-Sociological Theory. Princeton, NJ: Princeton University Press.

Conley, Carolyn. 1999. The Agreeable Recreation of Fighting. Journal of Social History 33(1): $57-72$.

Contreras, Randol. 2013. The Stickup Kids: Race, Drugs, Violence, and the American Dream. 
Berkeley, CA: University of California Press.

Cooney, Mark. 1998. Warriors \& Peacemakers: How Third Parties Shape Violence. New York: New York University Press.

Cressey, Donald. 1953. Other People's Money: A Study in the Social Psychology of Embezzlement. Glencoe, IL: The Free Press.

Csíkszentmihályi, Mihály. 1990. Flow: The Psychology of Optimal Experience. New York: Harper and Row.

Decker, Scott and Barrik van Winkle. 1996. Life in the Gang. Cambridge, UK: Cambridge University Press.

Dollard, James, Leonard Doob, Neal Miller, Orval Mowrer, and Robert Sears. 1939. Frustration and Aggression. New Haven, CT: Yale University Press.

Durkheim, Emile. 1912/1995. The Elementary Forms of Religious Life. New York: The Free Press.

Emerson, Robert. 1981. On Last Resorts. American Journal of Sociology 87: 1-20.

Emerson, Robert and Sheldon Messinger. 1977. The Micro-Politics of Trouble. Social Problems 
25(1): 121-134.

Epstein, Lee and Gary King. 2002. The Rules of Inference. The University of Chicago Law Review 69: 1-33.

Erikson, Kai. 1966. Wayward Puritans. New York: Wiley \& Sons.

Espelage, Dorothy, Melissa Holt, and Rachel Henkel. 2003. Examination of Peer-Group Contextual Effects on Aggression During Early Adolescence. Child Development 74(1): 205220.

Farrington, David, Leonard Berkowitz, and Donald West. 1982. Differences between Individual and Group Fights. British Journal of Social Psychology 21(4): 323-333.

Ferrell, Jeff. 1997. Criminological Verstehen: Inside the Immediacy of Crime. Justice Quarterly 14(1): 3-23.

Ferrell, Jeff. 2012. Autoethnography. In The SAGE Handbook of Criminological Research Methods, ed. Gadd, D., S. Karstedt, and S. Messner 218-230. London: SAGE.

Foucault, Michel. 1977. Discipline and Punish: The Birth of the Prison. New York: Vintage Books. 
Freud, Sigmund. 1907/1959. The Collected Papers of Sigmund Freud. New York: Basic Books.

Freud, Sigmund. 1930/1989. Civilization and Its Discontents. New York: W. W. Norton \& Company.

Garfinkel, Harold. 1956. Conditions of Successful Degradation Ceremonies. American Journal of Sociology 61: 420-424.

Garfinkel, Harold. 1967. Studies in Ethnomethodology. Cambridge, UK: Polity Press.

Garot, Robert. 2007a. "Where You From": Gang Indentity as Performance. Journal of Contemporary Ethnography 36: 50-84.

Garot, Robert. 2007b. Non-Violence in the Inner-City: Decent and Street as Strategic Resources. Journal of African American Studies. 10(4): 94-111.

Garot, Robert. 2010. Who You Claim: Performing Gang Identity in School and on the Streets. New York: New York University Press.

Gasking, Douglas. 1955. Causation and Recipes. Mind 64 (256): 479-487.

Geertz, Clifford. 1973. The Interpretation of Cultures. New York: Basic Books. 
Girard, René. 1977. Violence and the Sacred. Baltimore, MD: Johns Hopkins University Press.

Glaser, Barney and Anselm Strauss. 1967. The Discovery of Grounded Theory: Strategies for Qualitative Research. Chicago: Aldine de Gruyter.

Goffman, Erving. 1967. Interaction Ritual. New York: Anchor Books.

Goffman, Erving. 1971. Asylums: Essays on the Social Situation of Mental Patients and Other Inmates. Garden City, NY: Anchor Books.

Gorn, Elliot. 1985. "Gouge and Bite, Pull Hair and Scratch”: The Social Significance of Fighting in the Southern Backcountry. American Historical Review 90(1): 18-43.

Gottfredson, Michael and Travis Hirschi. 1990. A General Theory of Crime. Stanford, CA: Stanford University Press.

Grazian, David. 2003. Blue Chicago: The Search for Authenticity in Urban Blues Clubs. Chicago: University of Chicago Press.

Hagan, John and Holly Foster. 2001. Youth Violence and the End of Adolescence. American Sociological Review 66(6): 874-899.

Hagedorn, John. 1988. People and Folks: Gangs in a Rustbelt City. Milwaukee, WI: University 
of Wisconsin Press.

Heritage, John. 1984. Garfinkel and Ethnomethodology. Cambridge, UK: Polity Press.

Horowitz, Ruth and Gary Schwartz. 1974. Honor, Normative Ambiguity, and Gang Violence. American Sociological Review 39: 238-251.

Jackson-Jacobs, Curtis. 2004a. Taking a Beating: The Narrative Gratifications of Fighting as an Underdog. In Cultural Criminology Unleashed. ed. Hayward, K., J. Ferrell, W. Morrison \& M. Presdee 231-244. London: Glasshouse Press.

Jackson-Jacobs, Curtis. 2004b. Hard Drugs in a Soft Context: Managing Trouble and Crack Use on Campus. The Sociological Quarterly 25(4): 835-856.

Jackson-Jacobs, Curtis. 2009. Tough Crowd: An Ethnographic Study of the Social Organization of Fighting. Doctoral Dissertation, Department of Sociology, University of California at Los Angeles.

Jackson-Jacobs, Curtis. 2011. Social Organization in Violence: An Analysis of Witnesses' Video-Recordings of Violence Encounters. Paper presented at the Third International Crime, Media, and Popular Culture Studies Conference, Indiana State University at Terre Haute.

Johnson, Michael. 1995. Patriarchal Terrorism and Common Couple Violence: Two Forms of 
Violence against Women. Journal of Marriage and Family 57 (2): 283-294.

Jones, Nikki. 2010. Between Good and Ghetto: African American Girls and Inner-City Violence. New Brunswick, NJ: Rutgers University Press.

Katz, Jack. 1974. Essences as Moral Identities: Verifiability and Responsibility in Imputations of Deviance and Charisma. American Journal of Sociology 80(6): 1369-1390.

Katz, Jack. 1988. Seductions of Crime. New York: Basic Books.

Katz, Jack. 1999. How Emotions Work. Chicago: University of Chicago Press.

Katz, Jack. 2001. “Analytic Induction.” In International Encyclopedia of the Social Sciences, ed. N. Smelser and P. Baltes 480-484. New York: Elsevier.

Katz, Jack and Curtis Jackson-Jacobs. 2004. The Criminologists' Gang. In The Blackwell Companion to Criminology, ed.C. Sumner, 91-124. Oxford, UK: Blackwell.

King, Anthony. 1995. Outline of a Practical Theory of Football Violence. Sociology 29 (4): 635641.

Labov, William. 1972. Language in the Inner City: Studies in the Black English Vernacular. Philadelphia, PA: University of Pennsylvania Press. 
Labov, William. 1982. Speech Actions and Reactions in Personal Narrative. In Georgetown University Round Table on Language and Linguistics 1981, ed. D. Tannen, 219-247.

Washington, DC: Georgetown University Press.

Lee, Jooyoung. 2009. Battlin' on the Corner: Techniques for Sustaining Play. Social Problems 56(3): 578-598.

Lindesmith, Alfred. 1947. Opiate Addiction. Bloomington, IN: Principia Press.

London, Jack. 1903. The Call of the Wild. New York: Grosset \& Dunlap Publishers. Luckenbill, David. 1977. Criminal Homicide as a Situated Transaction. Social Problems 25(3): 176-186.

Luckenbill, David. 1981. Generating Compliance: The Case of Robbery. Urban Life 10(1): 2546.

Lyng, Stephen. 1998. Dangerous Methods: Risk Taking and the Research Process. In Ethnography at the Edge. ed. J. Ferrell and M. Hamm 221-251. Boston: Northeastern University Press

Lyng, Stephen. 1990. Edgework: A Social-Psychological Analysis of Voluntary Risk Taking. American Journal of Sociology 95(4): 851-886. 
MacIver, Robert. 1942/1964. Social Causation. New York: Harper Torchbook.

Marsh, Peter, Elizabeth Rosser, and Rom Harré. 1978. The Rules of Disorder. London: Routledge and Keegan Paul.

Mauss, Marcel. 1933/1973. Techniques of the Body. Economy and Society 2(1): 70-88.

McAndrew, Craig, and Robert Edgerton. 1969. Drunken Comportment: A Social Explanation. Chicago: Aldine.

Mead, George Herbert. 1934/1962. Mind, Self, and Society: From the Standpoint of a Social Behaviorist. Morris, C. (editor). Chicago: University of Chicago Press.

Merton, Robert K. 1987. Three Fragments from a Sociologist's Notebooks: Establishing the Phenomenon, Specified Ignorance, and Strategic Research Materials. Annual Review of Sociology 13: 1-28.

Monkkonnen, Eric. 2001. Murder in New York City. Berkeley, CA: University of California Press.

Morrill, Calvin, Christine Yalda, Michael Musheno, and Cindy Bejarano. 2000. Telling Tales in School: Youth Culture and Conflict Narratives. Law \& Society Review 34(1): 101-144. 
Newman, Katherine. 2004. Rampage: The Social Roots of School Shootings. New York: Basic Books.

Orcutt, James. 1978. Normative Definitions of Intoxicated States: A Test of Several Sociological Theories. Social Problems 25 (4): 385-396.

Pagliai, Valentina. 2000. Lands I Came to Sing: Negotiating Identities and Places in the Tuscan Contrasto. Pragmatics 10(1): 125-46.

Paschall, Mallie, TS Ennett, and Robert Flewelling. 1996. Relationships among Family Characteristics and Violent Behavior by Black and White Male Adolescents. Journal of Youth and Adolescence 25(1): 177-197.

Polanyi, Michael. 1958. Personal Knowledge: Towards a Post-Critical Philosophy. Chicago: University of Chicago Press.

Polk, Kenneth. 1999. Males and Honor Contest Violence. Homicide Studies 3(1): 6-29.

Ragin, Charles. 2008. Redesigning Social Inquiry: Fuzzy Sets and Beyond. Chicago: University of Chicago Press.

Raymond, Geoffrey. 2009. Towards a Sociology of the Body-in-Action: The Body and its 
Multiple Commitments. February 4, 2009. Department of Sociology, University of California at Los Angeles.

Sacks, Harvey. 1987. On the Preferences for Agreement and Contiguity in Sequences of Conversation. In Talk and Social Organization, ed. G. Button and J. Lee, 54-69. Clevedon, UK: Multilingual Matters.

Sacks, Harvey. 1967-1968/1992. Lectures on Conversation. Jefferson, G (editor). Oxford: Blackwell Press.

Sanchez-Janksowski, Martin. 1991. Islands in the Street: Gangs and American Urban Society. Berkeley, CA: University of California Press.

Sanders, William. 1994. Gangbangs and Drive-bys: Grounded Culture and Juvenile Gang Violence. New York: Aldine de Gruyter.

Saner, Hillary and Phyllis Ellickson. 1996. Concurrent Risk Factors for Adolescent Violence. Journal of Adolescent Health 19(2): 94-103.

Sarabia, Daniel and Thomas Shriver. 2004. Maintaining Collective Identity in a Hostile Environment: Confronting Negative Public Perception and Fractional Divisions within the Skinhead Subculture. Sociological Spectrum 24(3): 267-294. 
Schegloff, Emmanuel. 1987. Analyzing Single Episodes of Interaction: An Exercise in Conversation Analysis. Social Psychology Quarterly 50(2): 101-114.

Schelling, Max. 1960. The Strategy of Conflict. Cambridge, MA: Harvard University Press.

Schinkel, Willem. 2010. Aspects of Violence: A Critical Theory. New York: Palgrave MacMillan.

Schutz, Alfred. 1962. Collected Papers, Vol. I: The Problem of Social Reality. The Hague, Netherlands: Martinus Nijhoff.

Schutz, Alfred and Thomas Luckman. 1973. The Structures of the Life-World. Evanston, IL: Northwestern University Press.

Short, James and Fred Strodtbeck. 1968. Why Gangs Fight. In Gang Delinquency and Delinquent Subcultures, ed. J. Short, 246-255. New York: Harper \& Row.

Simmel, Georg. 1905/1955. Conflict. Glencoe, IL: Free Press.

Sudnow, David. 1978. Ways of the Hand: The Organization of Improvised Conduct. London: Routledge \& Keegan Paul.

Sullivan, Mercer. 1989. Getting Paid: Youth Crime and Unemployment in Three Urban 
Neighborhoods. New York: Cornell University Press.

Tomsen, Stephen. 1997. A Top Night: Social Protest, Masculinity, and the Culture of Drinking Violence. British Journal of Criminology 37: 90-102.

Wacquant, Loïc. 2004. Body \& Soul: Notebooks of an Apprentice Boxer. New York: Oxford University Press.

Webb, Eugene, Donald Campbell, Richard Schwartz, and Lee Sechrest. 1966. Unobtrusive Measures: Nonreactive Research in the Social Sciences. Chicago: Rand McNally.

Wilson, James Q. and Richard Herrnstein. 1985. Crime and Human Nature. New York: Simon and Schuster.

Winlow, Simon and Steve Hall. 2006. Violent Night: Urban Leisure and Contemporary Culture. Oxford, UK: Berg.

Wolfgang, Marvin. 1957. Victim-Precipitated Criminal Homicide. Journal of Criminal Law, Criminology and Police Science 48: 1-11.

Wood, Robert. 1999. The Indigenous, Nonracist Origins of the American Skinhead Subculture. Youth \& Society 31(2): 131-151. 
Zimring, Franklin and James Zeuhl. 1986. Victim Injury and Death in Urban Robbery: A Chicago Study. Journal of Legal Studies 15(1): 1-40.

Znaniecki, Florian. 1934. The Method of Sociology. New York: Farrar \& Rinehart. 